\title{
Protein Binding to Gold Colloids
}

\section{Ossi Horovitz ${ }^{1}$, Gheorghe Tomoaia², Aurora Mocanu ${ }^{1}$, Traianos Yupsanis ${ }^{3}$ and Maria Tomoaia-Cotisel ${ }^{1}$}

\footnotetext{
1 "Babes-Bolyai" University of Cluj-Napoca, Faculty of Chemistry and Chemical Engineering, Kogalniceanu Str., no. 1, 400028 Cluj-Napoca, Romania

2 "Iuliu Hatieganu" University of Medicine and Pharmacy, Department of Orthopedic Surgery, Traian Mosoiu Str., no. 47, 400132 Cluj-Napoca, Romania

${ }^{3}$ Aristotelian University, School of Chemistry, Laboratory of Biochemistry, 54006 Thessaloniki, Greece

E-mail: ossihor@yahoo.com
}

\begin{abstract}
Gold nanoparticles (size from 10 to $50 \mathrm{~nm}$ ) were synthesized by three different methods and were characterized by UV-Vis spectroscopy and transmission electron microscopy (TEM). The shape and size distribution of gold nanoparticles were determined. The interaction of major storage protein extracted and purified from aleurone cells of barley with the gold colloids has been examined using absorption UV-Vis spectroscopy and TEM observations. These investigations evidence the binding of aleurone protein to gold nanoparticles. This binding might occur by electrostatic forces between the negatively charged citrate capped gold particles and the positively charged groups of the protein (e.g., arginine and lysine residues).
\end{abstract}

\section{Introduction}

The specific optical, electronic and magnetic properties of gold nanoparticles, as well as their potential and actual applications in biology, medicine and catalysis, make them a preferred object of investigation in the fields of nanoscience and nanotechnology.

Many chemical methods were developed for the preparation of gold nanoparticles [1, 2], whereas the most common use the reduction of a gold(III) or gold(I) compound, mostly hydrogene tetrachloroaurate(III), by a reducing agent. The classical Turkevich method [3] involves reduction of an aqueous $\mathrm{HAuCl}_{4}$ solution by trisodium citrate. Citrate initially acts as a reducing agent for $\mathrm{Au}(\mathrm{III})$, respectively $\mathrm{Au}(\mathrm{I})$, to reduce them to $A u(0)$, and later as the stabilizing agent, by forming an electrically charged adsorption layer on the gold nanoparticles surface. In order to obtain particles of predictable size (e.g., between 15 and $150 \mathrm{~nm}$ ), the ratio between the reagents was varied [4], and tannic acid was added, which is believed to reduce the gold particle size [5].

Different reducing agents were also used. The findings show that the greater the power and concentration of the reducing agent, generally, the smaller the resultant gold particles in the suspension will be. Such agents were ascorbate (i.e. $12 \mathrm{~nm}$ gold particles) [2, 6], white phosphorus in diethyl ether (i.e. $4 \mathrm{~nm}$ gold particles) [2, 6], formaldehyde solution [7] or sodium borohydride $\mathrm{NaBH}_{4}$ [8].

Other methods of obtaining gold nanoparticles, including the two-phase Brust-Schiffrin method [9] usually involve organic solvents [1]. Different thiol-coordinated functional groups such as thiopronin, glutathione, succinic acid, sulfonic acid have been used as capping agents for these particles. Recently, it is shown that amines can also stabilize nearly covalently gold nanoparticles in aqueous solutions and amine-capped nanoparticles can be dried and the obtained powder is readily redispersible in water and also in other solvents [10].

Gold nanoparticles present a single strong absorption band in the visible range between 510 and $550 \mathrm{~nm}$. This band is due to surface plasmon resonance (SPR) caused by collective oscillations of the 6 s conduction electrons of nanoparticles (the electron gas at the surface of nanoparticles) with a size in the order of $1 / 10$ from the wavelength of the incident light [1]. These optical properties of nanoparticles can be described using Mie scattering theory [11], as a result of surface plasmon absorption and scattering. The wavelength of the absorption peak depends on several factors, like particle size [12, 13], inter-particle distance, dielectric constant of the surrounding media (dispersion medium) and adsorbates [14]. With increasing particle size, the absorption maximum shifts to a longer wavelength, while the width of the absorption spectra relates to the size range of nanoparticles.

The position of the maximum and the bandwidth are also influenced by the particle shape [15] and the temperature. For coated gold nanoparticles, the characteristics of the surface coating layer is also important, i.e. its dielectric 


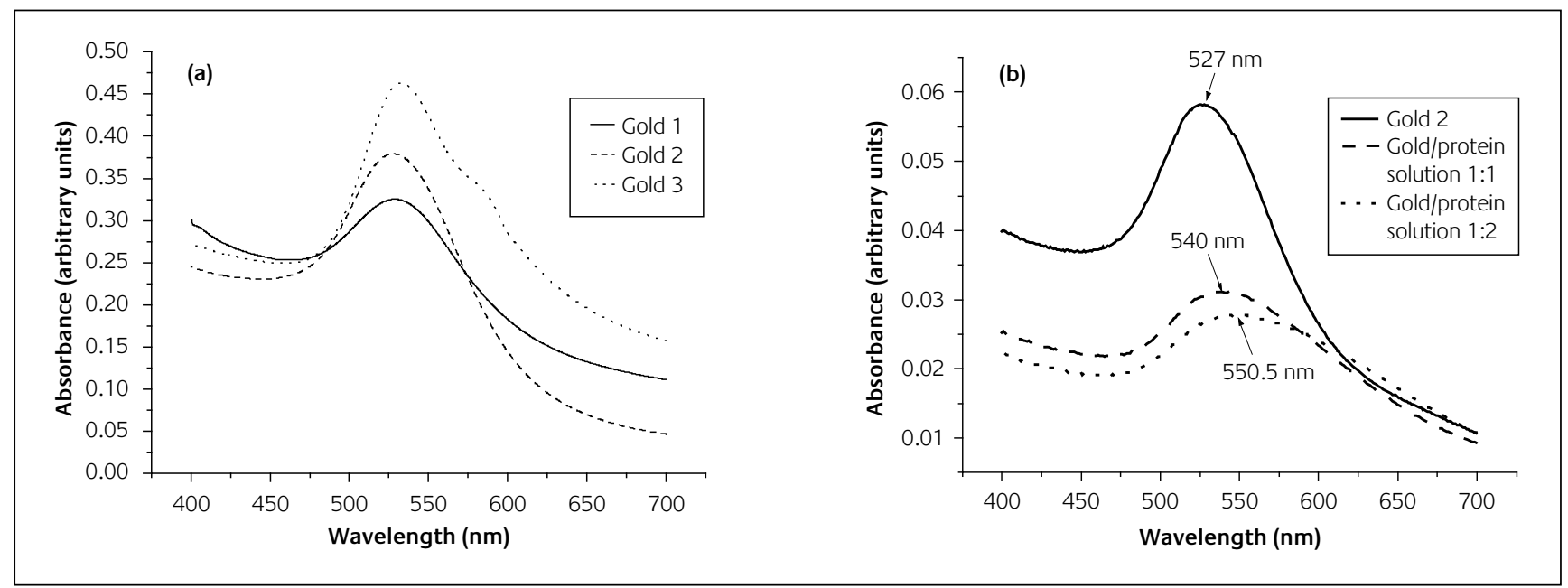

\section{Figure 1}

Optical spectra of Au colloidal solutions, (a, samples 1-3) and of a gold colloidal solution (b, sample 2) with variable amounts of protein (200 mg/L) solution; the volume ratio is given on the Figure $1 \mathrm{~b}$ and in Table 1

\section{Table 1}

Wavelengths of the absorption maxima $\lambda_{\max }$ for the gold colloid (sample 2) with protein solutions of about $200 \mathrm{mg} / \mathrm{L}$

\begin{tabular}{lllllll}
\hline Gold colloid sample 2 & \multicolumn{5}{c}{$\lambda_{\max }=\mathbf{5 2 7} \mathbf{~ n m}$} \\
\hline $\begin{array}{l}\text { Gold colloid / protein } \\
\text { solution (Volume ratio) } \\
\lambda_{\max }(\mathrm{nm})\end{array}$ & $10 / 1$ & $5 / 1$ & $2.5 / 1$ & $1 / 1$ & $1 / 2$ & $1 / 9$ \\
\hline
\end{tabular}

constant, the thickness of the coating, as well as the fraction of the total particle volume occupied by the metallic core. Another important factor is the extent of aggregation of the particles $[12,13]$.

In the present paper, we report the synthesis of three gold colloids, with the average nanoparticle size from 10 to 50 $\mathrm{nm}$, and their characterization using UV-Vis spectra and TEM observations. Also, for the first time, we report the results on the interactions of the major aleurone protein of barley with gold nanoparticles in colloidal aqueous solutions, using the same experimental (UV-Vis and TEM) methods.

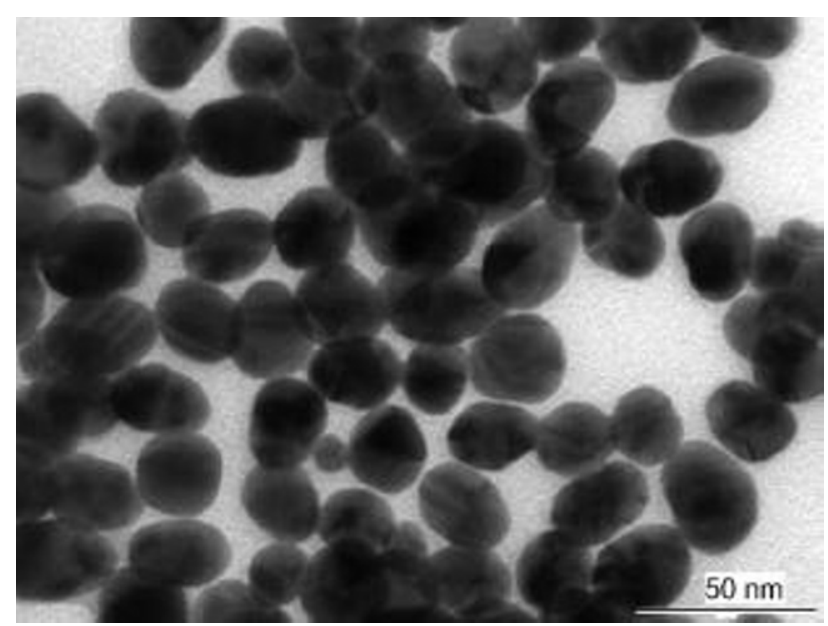

Figure 2

TEM images of gold nanoparticles sample 1
In the next report, we study the influence of gold nanoparticles auto-assembled as an interfacial film on the binding of the major aleurone protein, using UV-Vis spectroscopy and AFM investigations.

\section{Experimental Section}

\section{Materials}

Three colloidal gold aqueous solutions were prepared, namely: two of them by $\mathrm{HAuCl}_{4}$ reduction [16] with trisodium citrate.

Sample 1. The preparation of sample 1 was adapted from [17]. A $2 \cdot 10^{-3} \mathrm{M} \mathrm{HAuCl}_{4}$ solution $(50 \mathrm{~mL})$ was refluxed with magnetic stirring. Then $50 \mathrm{~mL} 8 \cdot 10^{-3} \mathrm{M}$ trisodium citrate solution was added to the boiling $\mathrm{HAuCl}_{4}$ solution. The mixture was refluxed for $1 \mathrm{~h}$, while the colour turned to red. The solution was left to cool at room temperature. The gold content in the final sol is $197 \mathrm{mg} / \mathrm{L}$.

Sample 2. The preparation of sample 2 was adapted from [18]. An amount of $200 \mathrm{~mL}$ solution of $\mathrm{HAuCl}_{4} \cdot 3 \mathrm{H}_{2} \mathrm{O}(0.005 \%$

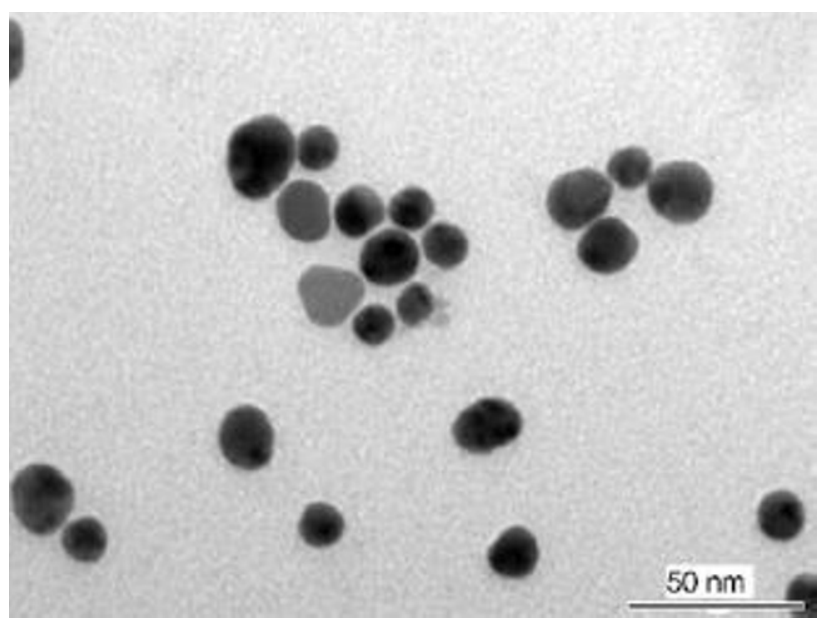

Figure 3

TEM images of gold nanoparticles sample 2 
w/w) was stirred vigorously and refluxed. To the boiling solution $15.3 \mathrm{mg}$ trisodium citrate $\left(\mathrm{Na}_{3} \mathrm{C}_{6} \mathrm{H}_{5} \mathrm{O}_{7} \cdot 2 \mathrm{H}_{2} \mathrm{O}\right)$, solved in a minimum amount of water, was added. After colour change to reddish, the heat was turned off and the solution was allowed to cool overnight to room temperature. The gold content in the final sol is $25 \mathrm{mg} / \mathrm{L}$.

Sample 3. The sample 3 was prepared as described elswhere [19]. The amount of $320 \mathrm{~mL}$ of $10^{-3} \mathrm{M}$ sodium disulfitoaurate (I), $\mathrm{Na}_{3} \mathrm{Au}\left(\mathrm{SO}_{3}\right)_{2}$, solution was mixed with 225 $\mathrm{mL} 0.075 \mathrm{M}$ trisodium citrate solution. The mixture, heated on oil bath, was refluxed with stirring for $6 \mathrm{~h}$. The gold content in the final sol is $108 \mathrm{mg} / \mathrm{L}$.

The tetrachloroauric (III) acid was purchased from Merck (high purity above 99.5\%). The trisodium citrate dihydrate $\left(\mathrm{Na}_{3} \mathrm{C}_{6} \mathrm{H}_{5} \mathrm{O}_{7} \cdot 2 \mathrm{H}_{2} \mathrm{O}\right)$ was obtained from Sigma Aldrich (high purity above 99\%). All chemicals were used without further purification.

All solutions were made with ultra pure water with resistivity of at least $18 \mathrm{Mohm} \cdot \mathrm{cm}$ and the surface tension at the interface with air of $72 \mathrm{mN} \mathrm{m}^{-1}$ at $25^{\circ} \mathrm{C}$ [20].

All resulting solutions of colloidal gold particles were stored in brown bottles and kept at $4^{\circ} \mathrm{C}$.

The protein used is the major storage protein from aleurone cells of barley (Hordeum vulgare L.) extracted and purified as shown elsewhere [21]. In order to study the influence of major aleurone protein, the protein was previously dissolved in water to achieve homogeneous mixing of the added protein to the gold colloid solutions. The protein solution of $200 \mathrm{mg} / \mathrm{L}$ made in ultra pure water was added in different proportions to the colloidal gold aqueous solutions. The $\mathrm{pH}$ of the major aleurone protein solution was about 5.6.

\section{Methods}

The UV/Vis absorption spectra of the colloidal gold solutions and of the protein solutions were recorded using a Jasco UV/Vis V-530 spectrophotometer in the 190-900 nm wavelengths range.

The gold nanoparticles suspension in the absence and in the presence of protein was deposited and air-dried on the TEM specimen grid and observed with a transmission electron microscope (TEM: JEOL - JEM 1010). TEM specimens consist of carbon or collodion coated copper grids. TEM images have been recorded with a JEOL standard software.

\section{Results and discussion}

The visible absorption spectra of the three samples of gold aqueous colloidal solutions are shown in Figure 1a. The solutions present well-defined absorption maxima at wavelengths $\lambda_{\max }$ of $529 \mathrm{~nm}$ (sample 1), $527 \mathrm{~nm}$ (sample 2) and $533 \mathrm{~nm}$ (sample 3 ) respectively (Table 2). These values are characteristic for plasmon (SPR) absorbance for nanometric Au particles. The shoulder observed at higher wavelength for sample 3 can be ascribed to an aggregation of the nanoparticles. The wavelength was not significantly modified, during at least one month after preparation, thus suggesting the stability of the colloidal solutions.

Adding diluted protein solutions (0.01, 0.1, 0.2 and $2 \mathrm{mg} / \mathrm{L})$ modifies only slightly the absorption spectrum for all the three gold colloidal solutions, while with the concentrated solution $(200 \mathrm{mg} / \mathrm{L})$ there is an important shift of the absorption maxima towards longer wavelength (for example, see Table 1 and Figure $1 \mathrm{~b}$ for gold sample 2). For sample 2, this maximum goes from $527 \mathrm{~nm}$ to $540 \mathrm{~nm}$ for a $1: 1$ ratio of the volumes of the colloidal gold and protein solution, and to $550 \mathrm{~nm}$ for the 1:2 ratio.

From the average size of the gold nanoparticles (see infra) and the molecular weight of the protein (approx. 135,000 $\mathrm{g} \mathrm{mol}^{-1}$ ) a volume ratio of 1:1 corresponds to a ratio between the number of gold nanoparticles and the number of protein molecules of about 1:1000. The shift is due to the change in the dielectric constant in the adsorption layer and to the size increase of gold particles by the adsorbed protein layer. Protein itself shows no absorption bands in the investigated range (200 $-900 \mathrm{~nm})$.

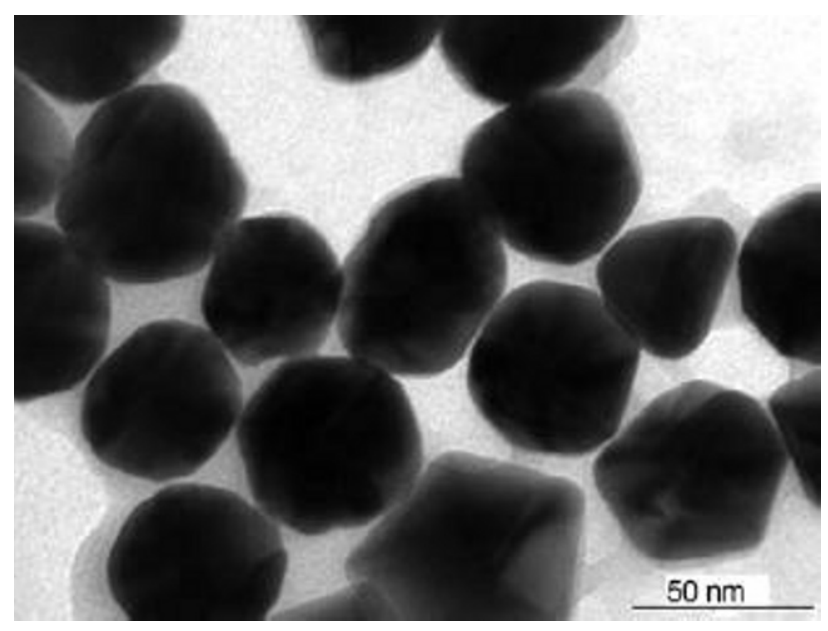

Figure 4

TEM images of gold nanoparticles sample 3

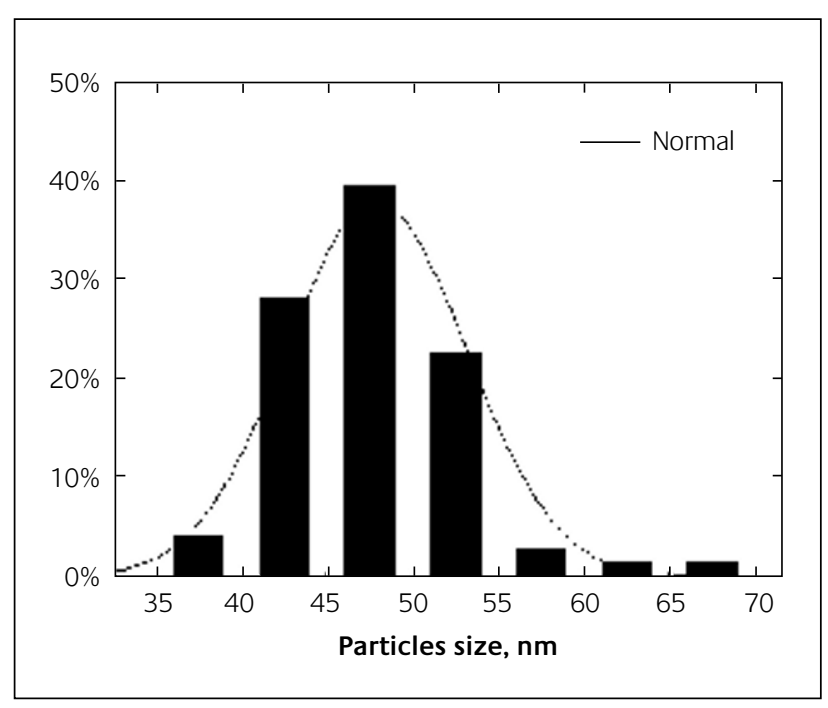

Figure 5

Histogram of size distribution for gold sample 3 


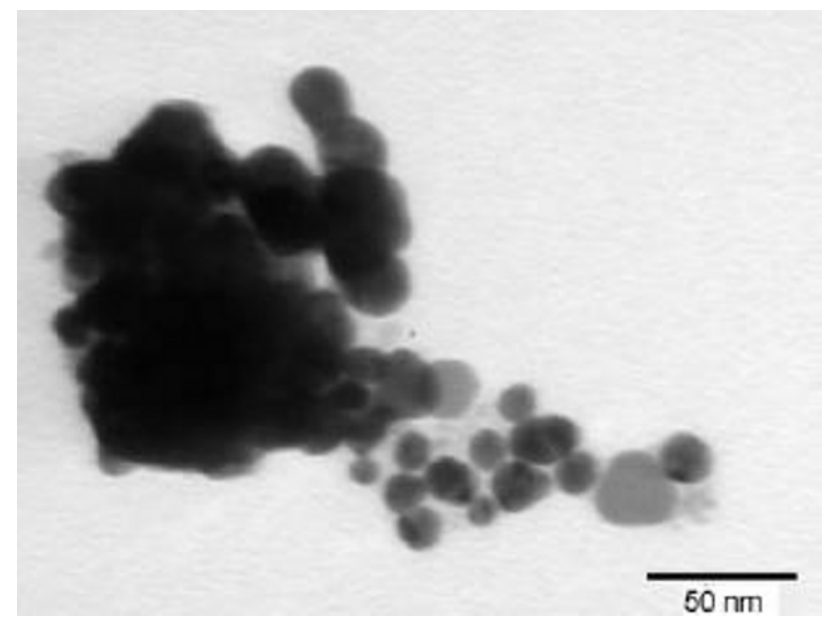

Figure 6 (a)

TEM image of gold nanoparticles (sample 2) with protein

The size of gold nanoparticles in colloidal solutions has been independently measured by TEM imaging. Some representative TEM images of Au colloids are shown in Figures 2-4. All figures are given in the same scale, so the differences in the size of particles are easy to see. For samples 1 and 2 the particles show mostly spherical or elliptical shape, just a few triangles, pentagons or hexagons are observed. On the other hand, for sample 3 these interesting shapes are more frequent (Figure 4).

From sizes of a great number of particles, measured on the TEM images, the average size (diameter) and the standard deviation were calculated. These values are 23.6 \pm 4.3

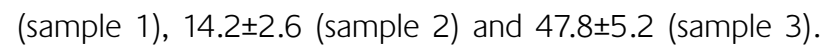
These and other characteristics of the gold samples are given in Table 2.

As an example, a histogram providing the size distribution of gold nanoparticles, obtained from TEM pictures, is given in Figure 5 for sample 3, together with the curve indicating the expected normal distribution. The sizes are consistent with the optical spectra given in Figure 1a, namely, the absorption maxima are shifted towards higher wavelengths with increasing size of the particles, while the width of the absorption band is correlated with the polydispersion of the system, i.e. with the standard deviation of the particle sizes.

The presence of protein on the gold nanoparticles deposited on TEM grids modifies dramatically the TEM images. Adding the protein leads to the agglutination of the gold nanoparticles (Figure 6a, the case of the sample 2 , and Figure $6 \mathrm{~b}$ corresponding to the sample 3) with the

Table 2

Characteristics of the gold samples. (SDEV is the standard deviation)

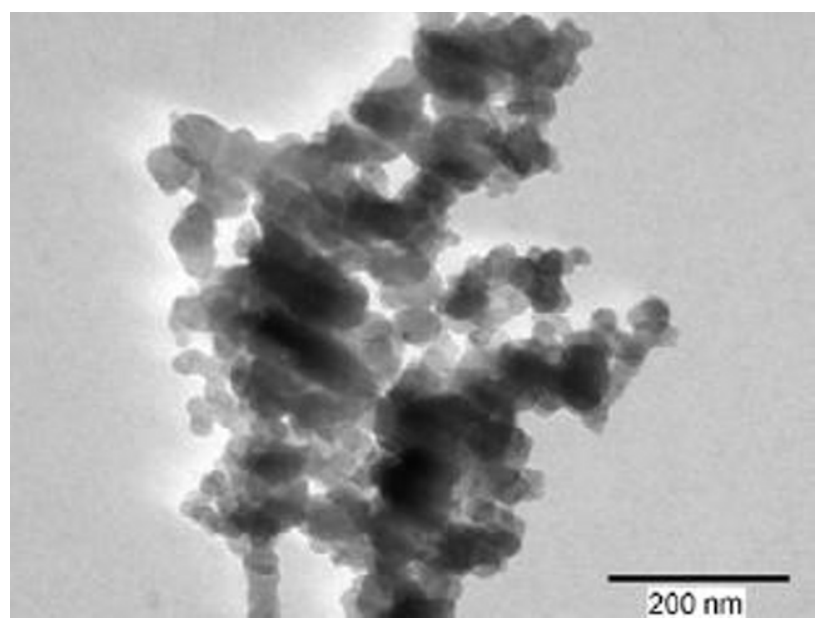

Figure 6 (b)

TEM image of gold nanoparticles (sample 3) with protein

development of large aggregates, particularly in the case of gold sample 2 .

A similar effect seems not to be present in the colloidal solutions of gold nanoparticles in the presence of protein, since only a slight broadening of the absorption band is observed (Figure 1b).

The major aleurone protein is related to 75 globulins present in other cereals and to the vicilin-type 75 globulins of legumes and cotton seed. It contains 4 subunits of about 20, 25, 40 and 50 kDa molecular weights [21].The Nterminal sequence of 16 amino acids in the protein [21] is given as follows, glutamic acid, glutamine, glycine, aspartic acid, serine, arginine, arginine, proline, tyrosine, valine, phenylalanine, glycine, proline, arginine, serine or histidine, and phenylalanine:

${ }^{1} X^{2}$ Glu ${ }^{3}$ Gln ${ }^{4}$ Gly ${ }^{5}$ Asp ${ }^{6}$ Ser ${ }^{7}$ Arg ${ }^{8}$ Arg ${ }^{9}$ Pro ${ }^{10}$ Tyr ${ }^{11}$ Val ${ }^{12}$ Phe ${ }^{13} \mathrm{Gly}{ }^{14} \mathrm{PrO}{ }^{15} \boldsymbol{A r g}{ }^{16}$ (Ser or His) ${ }^{17}$ Phe, where $X$ stands for the first amino acid of the $\mathrm{N}$-terminal of aleurone protein which was not identified. The secondary structure of this protein was recently investigated by advanced spectroscopy [22, 23].

As can be seen from the protein structure three arginine residues are present in the $\mathrm{N}$-terminal amino acid sequence. Also, a significant percent of arginine (7.9\%) and lysine (5.2\%) residues are found in the amino acid composition of barley aleurone protein [21]. The side amine groups of arginine and lysine identities, presumably correspond to protonated amine groups positively charged on the protein surface. Thus, the aleurone protein contains $-\mathrm{NH}_{3}{ }^{+}$side groups at the working $\mathrm{pH}$ of the solution. These groups are capable to form salt bridges with carboxylate from citrate adsorbed on gold nanoparticles.

\begin{tabular}{lccccccc}
\hline Sample & $\begin{array}{c}\text { Gold content } \\
{[\mathrm{mg} / \mathrm{L}]}\end{array}$ & $\begin{array}{c}\lambda_{\max } \text { abs. } \\
{[\mathrm{nm}]}\end{array}$ & $\begin{array}{c}\text { Average size } \\
{[\mathrm{nm}]}\end{array}$ & $\begin{array}{c}\text { SDEV } \\
{[\mathrm{nm}]}\end{array}$ & $\begin{array}{c}\text { Extreme values } \\
{[\mathrm{nm}]}\end{array}$ & $\begin{array}{c}\text { Atoms / particle } \\
\text { (average) }\end{array}$ & $\begin{array}{c}\text { Particles } \\
\text { per } \mathrm{cm}^{3}\end{array}$ \\
\hline 1 & 197 & 529 & 23.6 & 4.3 & $17.6-44.1$ & $4.6 \cdot 10^{5}$ & $1.5 \cdot 10^{12}$ \\
2 & 25 & 527 & 14.2 & 2.6 & $8.6-23.9$ & $8.8 \cdot 10^{4}$ & $8.6 \cdot 10^{11}$ \\
3 & 108 & 533 & 47.8 & 5.2 & $38.4-67.6$ & $3.4 \cdot 10^{6}$ & $1.0 \cdot 10^{11}$ \\
\hline
\end{tabular}


This type of binding is in substantial agreement with published data about the interaction of bovine serum albumin (BSA) with gold colloids, when citrate is present [24].

Besides this electrostatic interaction mechanism by salt bridges between positively charged aleurone protein molecules and negatively charged gold nanoparticles, the hydrophobic interactions among protein molecules within the protein layer adsorbed on the surface of gold nanoparticles should be taken into consideration. Furthermore, a direct binding of side amine groups of lysine and arginine identities positively charged of the aleurone protein with the gold nanoparticles surface negatively charged can not be excluded.

\section{Conclusions}

Absorption UV-Vis spectroscopy studies on colloidal gold aqueous solutions and investigations by transmission electron microscopy (TEM) provide an insight into their particulate structure and on their interaction with the major aleurone protein, which was extracted and purified from aleurone cells of barley.

The shape and sizes of gold particles were determined on TEM images. The sizes of gold nanoparticles are consistent with the obtained optical spectra and the absorption maxima are shifted towards higher wavelengths with increasing size of the particles, while the width of the absorption band is correlated with the polydispersion type of the systems.

From our experimental data it can be inferred that the protein is adsorbed on gold nanoparticles and forms a stable protein layer in colloidal aqueous solutions. The binding of protein to citrate coated gold nanoparticles in colloidal solutions might occur primarily by electrostatic interactions, such as salt-bridges between the negative citrate carboxylate and the lysine or arginine positively charged ammonium-type groups on the protein surface.

These findings suggest the protein film adsorbed on gold surface to be well suitable as a biological layer for industrial and biomedical applications.

\section{About the authors}

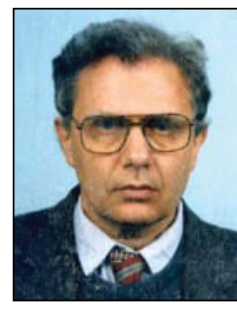

Dr. Ossi Horovitz is Professor of Physical Chemistry at the Babes-Bolyai University of Cluj-Napoca (Romania). His area of research includes computer chemistry (quantum chemistry, chemometry), macromolecules, physical chemistry of surfaces, nanosciences (colloidal gold).

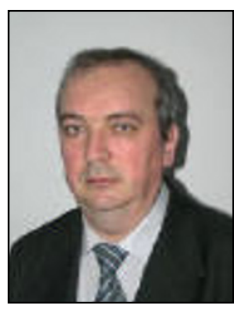

Dr. Gheorghe Tomoaia, M.D., is Associate Professor (Reader) in Orthopedic Surgery and Traumatology at Iuliu Hatieganu University of Medicine and Pharmacy, in Cluj-Napoca, and the Head of the Orthopedic Surgery Section at Clinic Hospital for Adults in Cluj-Napoca, Romania. His research is centered on orthopedic surgery and cutting edge topics of basic science related to nanostructured materials, including nanoparticles of gold with applications in nanomedicine.

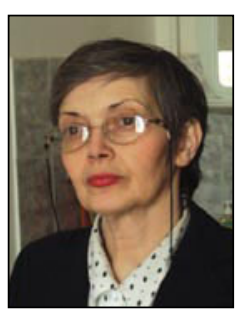

Dr. Aurora Mocanu is Associate Professor (Reader) and Scientific Researcher in the Department of Physical Chemistry at the Babes-Bolyai University of Cluj-Napoca (Romania). Her research interest is within the physical chemistry and biophysics of colloids and interfaces, and investigations by Langmuir-Blodgett technique and atomic force microscopy of nanostructured materials, including nanoparticles of gold.

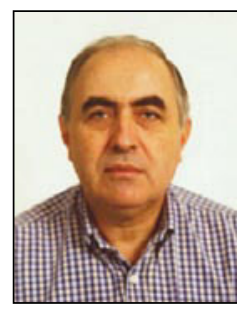

Dr. Traianos Yupsanis is Associate Professor of Biochemistry in the Department of Chemistry and Director of the Biochemistry Laboratory, at the Aristotle University of Thessaloniki in Greece. His research interest is directed to enzymes (nucleases, protein kinases, NDPkinases, peroxidases), plant proteins and gold nanoparticles, with applications in biotechnology and nanoscience.

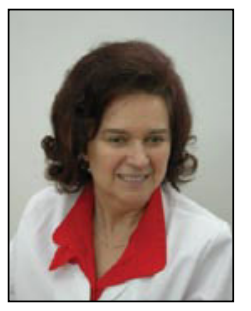

Dr. Maria Tomoaia-Cotisel is Professor of Physical Chemistry, Thermodynamics and Biophysics, and Director of the Physical Chemistry Center, at the Babes-Bolyai University of Cluj-Napoca (Romania). Her research interests are focused on wide physical chemistry topics, thermodynamics, molecular structure, biophysics and kinetics, as well as on colloid and surface chemistry, including biomembrane models, gold colloids and thin films, with applications in biotechnology and nanosciences. 


\section{Acknowledgement}

This research was financially supported by the Romanian Ministry of Education and Research (Scientific research project no.5/2005, within the Excellency Research Program).

\section{References}

1 M. C. Daniel and D. Astruc, Chem. Rev., 2004, 104, 293

2 M. A. Hayat (Editor), Colloidal Gold: Principles, Methods, and Applications, Acad. Press, New York, 1989

3 J. Turkevitch, P. C. Stevenson and J. Hillier, Discuss. Faraday Soc., 1951, 11, 55

4 G. Frens, Nature: Phys. Sci., 1973, 241, 20

5 J. W. Slot and H. J. Geuze, Eur. J. Cell Biol., 1985, 38, 87

6 G. T. Hermanson, Bioconjugate Techniques, Acad. Press, San Diego, 1996

7 K. Yamaguchi and H. Asakawa, Anal. Biochem., 1988, 172, 104

8 V. Patil, R. B. Malvamkar and M. Sastry, Langmuir, 1999, 15, 8197

9 M. Brust, M. Walker, D. Bethell, D. J. Schiffrin and R. J. Whyman, J. Chem. Soc., Chem. Commun., 1994, 801

10 M. Aslam, Lei Fu, Ming Su, K. Vijayamohananb and V. P. Dravid, J. Mater. Chem., 2004, 14, 1795

11 G. Mie, Ann. Phys. Leipzig, 1908, 25, 377

12 S. Link and M. El-Sayed, J. Phys. Chem. B, 1999, 103, 8410
13 K. L. Kelly, E. Coronado, L. L. Zhao and G. C. Schatz, J. Phys. Chem. B, 2003, 107, 668

14 V. Sun and Y. Xia, Anal. Chem., 2002, 74, 5297

15 M. B. Mohamed, V. Volkov, S. Link and M. A. El-Sayad, Chem. Phys. Lett., 2000, 317, 517

16 O. Horovitz, A. Mocanu, Gh. Tomoaia, L. Olenic, Gh. Mihǎilescu, O. Boroştean, A. Popoviciu, C. Crăciun, T. Yupsanis, and M. TomoaiaCotisel, in Convergence of Micro-Nano-Biotechnologies, Series in Micro and Nanoengineering, Romanian Acad. Press, Bucharest, 2006, pp. 133-147

17 O. Seitz, M. H. Chehimi, E. Cabet-Deliry, S. Truong, N. Felidj, C. Perruchot, S. J. Greaves and J. F. Watts, Colloids Surf. A. Physicochem.Eng.Asp., 2003, 218, 225

18 S. Chah, M. R. Hammond and R. N. Zare, Chemistry \& Biology, 2005, 12, 323

19 L. Olenic, Gh. Mihăilescu, S. Pruneanu, I. Bratu, A. R. Biriş, D. Lupu, Gh. Sigartău and L. B. Tudoran, Particulate Science and Technology, 2005, 23, 79

20 P. Joos, A. Tomoaia-Cotisel, A. J. Sellers and M. Tomoaia-Cotisel, Colloids and Surfaces. B. Biointerfaces, 2004, 37, 83

21 T. Yupsanis, S. R. Burgess, P. J. Jackson and P. R. Shewry, Journal of Experimental Botany, 1990, 41, 385

22 I. Bratu, M. Tomoaia-Cotisel, G. Damian and A. Mocanu, J. Optoelectronics Adv. Mat., 2007, 9 (3), 672

23 M. Tomoaia-Cotisel, A. Mocanu, N. Leopold, M. Vasilescu, V. Chiş and O. Cozar, J. Optoelectronics Adv. Mat., 2007, 9 (3), 637

24 S. H. Brewer, W. R. Glomm, M. C. Johnson, M. K. Knag and S. Franzen, Langmuir, 2005, 21, 9303 